OPEN ACCESS

Edited by:

Giray Gozgor,

Istanbul Medeniyet University,

Turkey

Reviewed by:

Ronnie Das,

Audencia Nantes School of

Management, France

Morteza Zihayat,

Ryerson University,

Canada

*Correspondence:

Zhibin Lin

zhibin.lin@durham.ac.uk

Specialty section:

This article was submitted to

Environmental Psychology,

a section of the journal

Frontiers in Psychology

Received: 17 August 2021 Accepted: 22 October 2021

Published: 11 November 2021

Citation:

LuX and Lin Z (2021) COVID-19,

Economic Impact, Mental Health, and

Coping Behaviors: A Conceptual

Framework and Future Research

Directions.

Front. Psychol. 12:759974

doi: 10.3389/fpsyg.2021.759974

\section{COVID-19, Economic Impact, Mental Health, and Coping Behaviors: A Conceptual Framework and Future Research Directions}

\author{
Xiaoqian $L^{1}$ and Zhibin $\operatorname{Lin}^{2 *}$ \\ ${ }^{1}$ School of Business Administration, Jimei University, Xiamen, China, ${ }^{2}$ Durham University Business School, Durham \\ University, Durham, United Kingdom
}

The COVID-19 pandemic has caused serious economic and social consequences. Recent research shows that the pandemic has not only caused a physical health crisis but also caused many psychological and mental crises. Based on the contemporary cognitivebehavioral models, this article offers a conceptual analysis of how the pandemic affects individual mental health and coping behaviors from the perspective of individual economic status, individual context, and social context. The analysis shows that (1) the pandemic has led to increased economic uncertainty, increased unemployment and underemployment pressure, increased income uncertainty, and different degrees of employment pressure and economic difficulties; (2) these difficulties have stimulated different levels of mental health problems, ranging from perceived insecurity (environmental, food safety, etc.), worry, fear, to stress, anxiety, depression, etc., and the mental health deterioration varies across different groups, with the symptoms of psychological distress are more obvious among disadvantageous groups; and (3) mental health problems have caused behavior changes, and various stress behaviors such as protective behaviors and resistive behaviors. Future research directions are suggested.

Keywords: COVID-19 pandemic, economic difficulty, employment difficulty, mental health, coping behavior

\section{INTRODUCTION}

The current COVID-19 pandemic is still ongoing, and it is concerning that we still do not know how long it will last and what long-term effects it will have. Despite the successful development of vaccines, the medical capacity to completely treat this disease is still limited. Non-pharmaceutical interventions (NPIs), such as increasing handwashing, reducing physical contact, wearing masks in public places, maintaining social distance, quarantine, and isolation, are still the main strategies for handling this pandemic (Van Bavel et al., 2020; Gössling et al., 2021). The social and economic consequences of the pandemic are devastating: almost half of the global workforce is at risk of losing their livelihoods, tens of millions are at risk of falling into extreme poverty, and millions of companies are facing existential threat (Alauddin et al., 2021). In addition to the pandemic itself, the economic impact of the crisis brings heavy psychological stress to individuals, causing mental health problems, and may trigger 
long-lasting behavior changes. Other pandemic-related factors may also cause psychological distress, including mandatory use of face masks (Wang et al., 2020a), lockdowns (Le et al., 2020), lack of access to medical services (Hao et al., 2020; Tee et al., 2021), dissatisfaction with health information (Tee et al., 2021), perceived discrimination (Wang et al., 2021), and stress about returning to work (Tan et al., 2020).

Prior behavioral science research focuses on perceived threats, stress, and coping (Van Bavel et al., 2020). In the early stages of the pandemic, the physical health risks associated with the COVID-19 pandemic have received extensive attention from the academic community (Mehta et al., 2020; Odayar et al., 2020), and there is growing research attention on the risks of mental health associated with the spread of the pandemic (Auerbach and Miller, 2020; Xiong et al., 2020; Wang et al., 2020a). The focal attention since the outbreak of the pandemic has been the psychological distress as a result of the pandemic itself (Jungmann and Witthöft, 2020) or the adverse economic impact of the pandemic (Bierman et al., 2021). However, it is still unclear how the pandemic control measures cause mental health problems through economic impact (Murakami et al., 2021). Many scholars believe that the measures taken during the pandemic may cause people to suffer more economic losses and fall into economic difficulties, thereby causing serious mental health problems (Timming et al., 2021), while some scholars believe that although the pandemic may cause huge economic losses, people's mental health status has not decreased (Murakami et al., 2021). Therefore, it is necessary to conduct a conceptual analysis of the economic impact of the pandemic and mental health by synthesizing the relevant findings in existing literature (Ali et al., 2021).

This study aims to develop a conceptual framework linking the pandemic to individual economic problems, unemployment, mental health, and behavior change. The main research questions are (1) what kind of individual economic stress has the pandemic caused? 2) what mental health problems have this individual economic stress caused, and to what extent? 3) does the mental health problem vary by different groups or individuals? 4) what kind of behaviors may be caused by the deterioration of mental health?

\section{THEORETICAL BACKGROUND}

According to the World Health Organization, mental health includes subjective well-being, self-efficacy, autonomy, ability, intergenerational dependence, intellectual or emotional potential. When there is a problem with mental health, there will be a decline in subjective well-being and various negative emotions (such as fear, nervousness, loneliness, and despair), and symptoms such as mental distress (such as anxiety, depression, and stress) will appear (Hossain et al., 2020). Mental health issues are considered as public health problems that are often affected by factors related to occupation, employment opportunities, and economic stress (Ali et al., 2021). Many scholars have examined the impact of economic poverty and unemployment on mental health (Jin et al., 1997). Disaster mental health research also shows that people generally suffer emotional or psychological distress following a disaster (Pfefferbaum and North, 2020).

\section{Mental Health Amid the Pandemic}

The World Health Organization (2020) proposes mental health indicators for the COVID-19 pandemic: painful symptoms and perceived danger. Mental distress is a short-term state of emotional distress, often driven by limited resources to manage stressors and daily life needs (Patel and Rietveld, 2020). The pandemic can become a major source of stress, especially in chronic anxiety and financial stress (Van Bavel et al., 2020). Mental distress has become the focus of research on mental health problems amid a large-scale crisis (Cheng et al., 2004; Wang et al., 2020b). Preliminary evidence suggests that symptoms of anxiety, depression, and self-reported stress are common psychological responses to the pandemic (Rajkumar, 2020). Salari et al. (2020) reported that the prevalence of stress was between 29.6 and $33.7 \%$. In addition to mental distress, the pandemic and corresponding interventions or preventive measures may make people feel insecure, fearful, uncertain, lonely, or isolated (Auerbach and Miller, 2020), which exacerbates the psychological distress (Pfefferbaum and North, 2020).

\section{Public Health Interventions}

Non-medical interventions or control measures during the pandemic may weaken social relationships that can help people to regulate emotions, cope with stress, and maintain adaptability (Rimé, 2009; Jetten et al., 2017; Williams et al., 2018), exacerbate feelings of loneliness and isolation (Hawkley and Cacioppo, 2010; Holmes et al., 2020), and become a risk factor for more serious mental health disorders (Cacioppo et al., 2006). The stresses experienced during the pandemic, especially the economic stress, may cause difficulties in interpersonal relationships, destroy psychological resources, and make normal interactions difficult (Karney, 2020). The impact of the pandemic interventions on mental health vary across different (employment) groups.

\section{Contemporary Cognitive-Behavioral Models and Mental Health}

The contemporary cognitive-behavioral models (Taylor and Asmundson, 2004; Asmundson et al., 2010) explore the key role of traits, triggering events, cognition, and behaviors in the development and maintenance of health anxiety, which can be used to analyze mental health problems during the pandemic period. Jungmann and Witthöft (2020) believe that during the pandemic, idiosyncratic health anxiety regulates the relationship between excessive online information search and viral anxiety, and adaptive emotions serve as a buffer between the two. The "Role Tension" model explores mental health issues from the perspective of role conflicts. It believes that individuals with multiple social roles may experience role conflicts, resulting in stress and adverse mental health (Oomens et al., 2007). The broader behavioral immune system theory (McKay et al., 2020) explores the specific path of disease anxiety, 
and believes that disgust tendency and sensitivity, and emotional response are all part of the behavioral immune system.

\section{CONCEPTUAL FRAMEWORK}

Figure 1 summarizes the themes from recent research findings in a conceptual framework.

\section{The Mechanism of COVID-19's Impact on Mental Health}

In addition to the pandemic itself, the lockdown, quarantine, or self-isolation policies that aim at fighting the pandemic, the involuntary underemployment or unemployment have led to individuals' economic difficulties and mental health problems of varying degrees for many people. The economic impact on individuals seems to further exuberate the suffering from the pandemic (Bierman et al., 2021).

\section{Employment Uncertainty}

Employment problems caused by the pandemic include involuntary unemployment (Piltch-Loeb et al., 2021), involuntary underemployment (Pierce et al., 2020; Ferry et al., 2021), employment uncertainty and insecurity (Wilson et al., 2020), job instability or inability to work (Sirviö et al., 2012), and others. Studies have shown that involuntary underemployment and/or unemployment are related to poor mental health (Dooley et al., 2000; Pharr et al., 2012), especially those who are unemployed during economic crises or recessions (Uutela, 2010; Drydakis, 2015; Fiori et al., 2016). It is reported that crisisrelated unemployment has led to a sharp rise in psychological disorders in low- and middle-income countries (Uutela, 2010). Despite the government measures to limit the economic impact, the involuntary underemployment or unemployment caused by the epidemic is prominent.

The impact of the pandemic on mental health varies (Pierce et al., 2020). Long-term unemployed people are most vulnerable to adverse mental health effects (Pierce et al., 2020), and those who were employed and retired in the months before the pandemic experience worse than expected mental health conditions (Ferry et al., 2021). Reduced work has different effects on the mental health of different groups. People who are in a poor health condition or self-isolated, and those who have their work reduced due to care responsibilities, have a higher degree of psychological distress (Ferry et al., 2021). The higher the work insecurity caused by the pandemic, the more severe the symptoms of depression (Wilson et al., 2020). As the pandemic continues, the fear of the pandemic itself has not increased mental health problems, but the deterioration of the labor market and the increase in the unemployment rate may intensify people's fear of unemployment, thereby increasing the degree of mental distress (Timming et al., 2021). In addition, due to the lockdown, people's work routines can be broken. Remote work, interruption of work activities due to lockdown measures, or increased workload due to the needs of the pandemic may also become factors affecting mental health (Rossi et al., 2020).

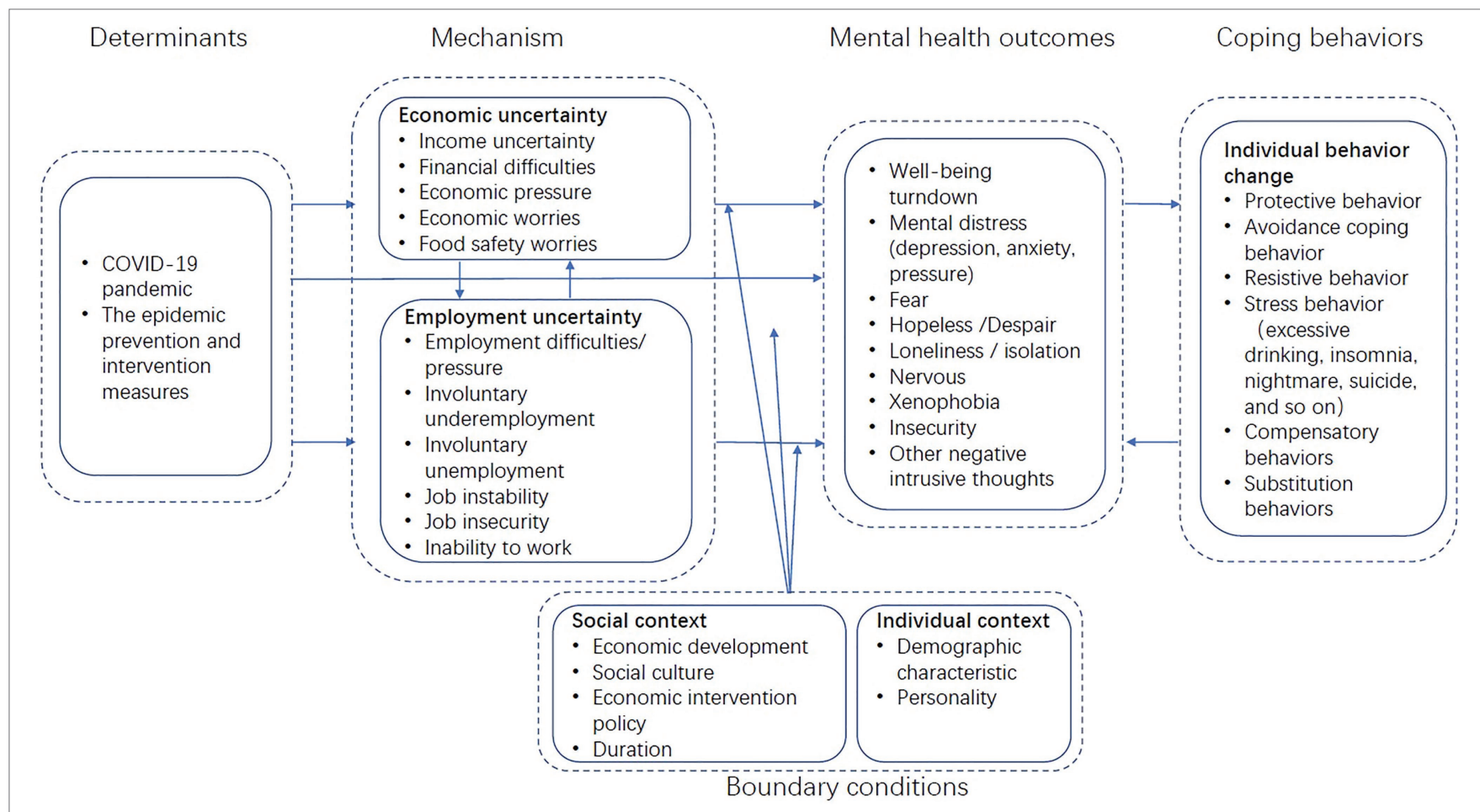

FIGURE 1 | Conceptual framework. 


\section{Economic Uncertainty}

The analysis of individual economic distress during the pandemic usually focus on short-term economic distress or economic stress, such as personal income uncertainty, personal financial difficulties, salary reduction and other economic (income) losses (Piltch-Loeb et al., 2021), as well as the expected long-term financial impact, such as depletion of savings and/or retirement funds (Piltch-Loeb et al., 2021).

There are two possible ways in which economic distress mediates the impact of the pandemic on psychological distress. One is the economic hardship or economic threat triggered by the pandemic itself. Individual economic loss, economic hardship, or economic threat was significantly associated with mental health (Ali et al., 2021). The pandemic has led to increased risks of depression, anxiety, stress, despair (Pettinicchio et al., 2021), insomnia (Hossain and Ali, 2021), and other common mental health problems. The negative relationship between economic distress and mental health may be a cumulative process. As exposure to distress extends, the average level of individual sufferings increases (Bierman et al., 2021). At the later stage in the pandemic, economic-related anxiety may be a major predictor of psychological distress (Timming et al., 2021).

Second, the unemployment and employment transition triggered by the pandemic affects the financial situation, which in turn affects psychological distress (Thomas et al., 2007). The economic recession triggered by the pandemic and the increase in economic uncertainty has led to business bankruptcy or downsizing, increased involuntary underemployment or unemployment, increased uncertainty in personal income, and increased likelihood of individuals or families experiencing financial difficulties and economic pressure, consequently triggering large scale mental health problems (Kimhi et al., 2020).

\section{Coping Behaviors}

The direct consequence of the pandemic's impact on mental health is the change of personal behavior and habits. Studies on past epidemics and pandemics have shown that negative emotions such as anxiety and stress during the epidemic may lead to different behavior patterns.

\section{Positive Defensive Behavior}

Humans are born with a set of defense systems against ecological threats (Mobbs et al., 2015). The main emotional response during a pandemic is fear. When people feel capable of responding to the threat of the pandemic, fear can cause individual behavior changes, but if people feel powerless, a defensive response occurs. Positive defensive behavior includes protective, defensive (avoidance), and substitution behaviors.

\section{Protective Behavior}

Mental health problems, such as high anxiety, during the epidemic may produce protective behaviors or compensatory behaviors (Wheaton et al., 2012), including washing hands frequently, wearing masks, increasing cleaning of items, social distancing, and other restrictions. Protective behavior can be voluntary (Rubin et al., 2009) or compliant with government regulation (Fragkaki et al., 2021). In addition, people actively engage in physical activities to cope with stress and anxiety (Ai et al., 2021).

\section{Defensive (Avoidance) Behavior}

Such behavior includes avoiding touching public goods, strangers, keeping a distance from "patients," avoiding densely populated places and public transport (Rubin et al., 2009), or even resigning from jobs that are perceived to be dangerous (Yin and Ni, 2021).

\section{Substitution Behavior (E.g. Using Technologies)}

Service provision based on digital and artificial intelligence technology has become a possible solution to replace human service provision (Nayal et al., 2021), triggering changes in consumer behavior by using technology-mediated services (such as robots) to replace manual services (Kim et al., 2021).

\section{Negative Resistance or Disruptive Behaviors Resisting Behavior}

People with low economic status are more likely to be vigilant about the public health information they receive are less willing to take recommended safety measures and may be more susceptible to "fake news" (Van Bavel et al., 2020). Misunderstandings and worries about the pandemic may also cause the public to refuse to comply with preventive measures (Prati et al., 2011). When people are less worried about the pandemic, they are less likely to engage in hygiene behaviors (such as washing hands), comply with social distance regulations, or be vaccinated if vaccines are available (Taylor, 2019). People also resist or refuse to participate in protective actions proposed by the government when they maintain an optimistic bias about the consequences of the outbreak (Fragkaki et al., 2021).

\section{Panic Consumption Behavior}

During the pandemic, a large number of customers stocked up on daily necessities to avoid the expected future threat due to uncertainty and panic arising from perceived scarcity, resulting in panic buying (Omar et al., 2021). People flooded hospitals and clinics unnecessarily when they misunderstood their minor illness as a sign of a serious infection (Asmundson and Taylor, 2020a, 2020b).

\section{Negative Idleness or Sabotage Behavior}

Anxiety is an important driving force of behavior (Taylor, 2019). Overly anxious individuals may engage in socially disruptive behaviors, especially for frontline service workers who are directly exposed to the outbreak (e.g., hotel staff), and may result in negative idleness (e.g., tardiness and absenteeism) or even disruptive behaviors or sabotage (Karatepe et al., 2021).

\section{Excessive Stress Behavior}

Anxiety and depression caused by the economic difficulties and employment difficulties caused by the crisis may result in various excessive stress behaviors, such as alcoholism (Ahmed 
et al., 2020) drug abuse (Nagelhout et al., 2017), even suicide (Milner et al., 2013), etc.

\section{The Boundary Conditions \\ Sociodemographic Factors}

The impact of economic or employment difficulties caused by the pandemic on mental health may be related to sociodemographic factors, including age, gender, ethnicity, family size, occupation, and income (Ferry et al., 2021). Age is one factor. Young people are more likely to have a higher level of anxiety and stress due to the pandemic and corresponding intervention measures than the elderly (Mann et al., 2020; Salameh et al., 2020; Hu and Qian, 2021; Ribeiro et al., 2021). Young people with mental health problems are especially likely to experience adverse health, well-being, and employment outcomes with longterm consequences (Bauer et al., 2021). However, there are also arguments that the elderly may have greater financial difficulties due to the increase in medical expenses during the epidemic, which may trigger mental health problems (Van Bavel et al., 2020), and the elderly's negative health consequences have been long-term ones (Van Bavel et al., 2020).

Gender is another one. Studies have shown that women are more likely to have higher levels of anxiety and stress when faced with possible physical health problems (Salameh et al., 2020; Ferry et al., 2021; Ribeiro et al., 2021). However, when there is the fear of losing their job and the economic anxiety surrounding this possibility, the psychological distress level is more serious for male than female employees (Timming et al., 2021). The third factor is ethnicity. Black and ethnic minority respondents have a higher level of economic anxiety (Mann et al., 2020). The study by Timming et al. (2021) shows that, compared with non-Hispanic respondents, Hispanic respondents are significantly more anxious about losing their jobs. The fourth factor is family size and the number of children. Respondents from families with no children have lower levels of economic anxiety (Mann et al., 2020). People living non-marital life have higher levels of psychological distress (Ferry et al., 2021).

Occupation is the fifth factor. People working at the emergency and customer-facing services, such as doctors, medical staff, police forces, frontline volunteer organizations, and bankers, have a higher risk of infection and subsequent mental stress (Shammi et al., 2020). The mental health of the unemployed, self-employed, and private professionals is worse than that of government professionals (Ali et al., 2020) for increased income (or economic) uncertainty caused by the pandemic (Patel and Rietveld, 2020) or for self-isolation or social distancing measures (Auerbach and Miller, 2020).

The sixth factor is income status. Most studies show that economic hardship resulting from the pandemic may make those disadvantaged groups (e.g., those living in poverty, low-income families, homeless, and refugees) the most vulnerable to experience the corresponding negative consequences (Van Bavel et al., 2020; Długosz, 2021; Hu and Qian, 2021). The mental health of people with disabilities and chronic diseases (Pettinicchio et al., 2021), living alone, and socially marginalized people is even more hostile (Kwong et al., 2020). However, some studies have suggested that the pandemic has a greater impact on the mental health of employees from high-income families (Ferry et al., 2021).

\section{Personality Traits and Psychological Conditions}

Personality traits and psychological conditions play an important role in the formation of mental health. Fisher et al. (2021) suggested that depressed and anxious psychological states during the epidemic were associated with diminished energy, functional efficiency, optimism, creativity, engagement, and the ability to focus and solve problems, all of which are necessary for social and economic participation. During the pandemic, those with low collective self-esteem, low responsibility, and low openness to experience have higher levels of economic anxiety, as do those with high levels of neuroticism, perceived vulnerability to illness, and attribution from large group activities (Mann et al., 2020). People with mental and physical health conditions may have higher levels of depression and anxiety because they are more likely to be unemployed and are prone to have higher levels of depression and anxiety (Hao et al., 2020; Kwong et al., 2020; Jung et al., 2021). Extreme loneliness is the main cause of psychological distress (Mikocka-Walus et al., 2021).

Emotional responses are part of the behavioral immune system. McKay et al. (2020) suggested that emotional reactions such as aversive tendencies and sensitivities are moderators of people's disease sensitivity and anxiety. High perceived risks, especially economic risks, are significantly associated with less positive emotions and more negative emotions, leading to more severe mental health problems (Han et al., 2021). The "optimism bias" may help individuals to avoid negative emotions (Van Bavel et al., 2020); however, it may not be conducive for people to engage in behavior change in response to non-pharmacological interventions while individuals with high levels of anxiety and high perceived severity are more likely to be involved in behavior change (Fragkaki et al., 2021).

\section{External Environment}

The complex factors of population density, health care capacity, limited resources and existing poverty, environmental factors, social structure, cultural norms, the number of people already infected, and the rapidly occurring community transmission of COVID-19 virus in a country or region can all contribute to public fears, which may lead to higher levels of mental health problems (Shammi et al., 2020).

Level of Economic Development or Socio-Economic Crisis People in low- and middle-income countries may have higher levels of stress, anxiety, and depression than those in highand middle-income countries (Tee et al., 2021). In lower-middleincome countries with socio-economic crises, political instability, dense population and limited resources, the stress and anxiety during the pandemic are high (Salameh et al., 2020). Even in high-income countries such as Canada and the United Kingdom, deterioration in mental health has been reported, and are increasing along with the extension of the pandemic period (Zajacova et al., 2020). 


\section{Government Economic Intervention Policies or Welfare \\ Policies}

Policies that reduce economic stress (e.g., economic interventions such as emergency response benefits) may alleviate the level of mental health deterioration in the early stages of a pandemic by reducing economic hardship and making people less worried about their economic situation (Zajacova et al., 2020). Vaccinebased interventions help to mitigate the economic impact of the outbreak (Meltzer et al., 1999).

\section{FUTURE RESEARCH DIRECTIONS}

\section{Mental Health Management Monitoring and Preventive Measures}

For policymakers, health authorities and health care professionals, it is very important to understand the impact of health anxiety on behavior. Future research should investigate the monitoring and preventive measures for different industries or different groups so as to help the government, service providers and employers understand the groups that should be given priority in mental health support (Ferry et al., 2021) and better conduct mental health rehabilitation. More studies are needed to examine the risk assessment of the pandemic, reliable risk communication with risk groups, the establishment of a cross-departmental management task force, and other measures.

\section{Social Protection Measures and Relief Programs}

Social protection measures include daily demand provision and social support (Jung et al., 2021) and cash transfer programs (Bauer et al., 2021). Future research should examine how to effectively use social protection measures (or relief plans) to solve the short-term and long-term effects of economic uncertainty caused by large-scale epidemics or economic crises on mental health. First, it is necessary to study how to support individual and family cash transfer programs to support young people's future life opportunities and break the vicious circle between mental illness and poverty that puts many young people at a disadvantage in socio-economic and mental health (Bauer et al., 2021). Second, it is essential to study the physical and mental health of the most economically disadvantaged during economic downturns (Holmes et al., 2020; Bierman et al., 2021), and specialized relief measures that target low-income populations (Shammi et al., 2020). Third, future research should consider both material and social supports in the examination of social protection measures (or relief programs). Fourth, future research attention needs to be paid to employee assistance programs, with a particular focus on mental health support for male employees.

\section{Intervention and Rehabilitation Measures}

Interventions to reduce economic uncertainty and economic risks should be a focus of future research from two aspects. Future research can be conducted around three aspects: First, to examine how to cultivate an individual's adaptive mentality to epidemics. Second, to explore individual resilience and psychological rehabilitation during and after a pandemic crisis (Hjemdal et al., 2011). Third, to explore the use of online interaction for social and mental health support. During the pandemic, providing remote mental health services is very important (Salameh et al., 2020). Future studies should examine online interactions to cultivate empathy and a sense of connection to enhance mental health (Schroeder et al., 2017; Waytz and Gray, 2018).

\section{Consequences of Mental Health}

There are currently few studies on the behavioral consequences of mental health, and more research is needed to understand the behavioral consequences of mental health caused by the epidemic. For example, the current research mainly focuses on panic buying behavior, and other compensatory behaviors can be added in the future, such as increasing the number of purchased goods, increasing specific food consumption, online shopping, and so on. Another example is to understand how individual factors (including health anxiety) specifically affect people's behavior in response to the pandemic (Asmundson and Taylor, 2020b). In addition, more research is required to examine the impact of the economic impact of the epidemic on the long-term behavior of individuals, especially stressful behaviors such as alcohol abuse, drug abuse, and suicide.

\section{Impact of Macro-Environmental Factors Culture}

In different cultural contexts (e.g., collectivism vs. individualism), economic distress and non-interventional measures such as social distancing may have different effects on mental health. From an evolutionary psychology perspective, when a group encounters a collective threat, strict rules may help the collective to coordinate and survive (Roos et al., 2015). In the face of a pandemic, a culture that is accustomed to putting freedom above safety can make community coordination difficult. However, currently there is little comparative research on mental health and behavior changes specifically for different cultures, and it is worthy of further thinking in the future.

\section{Ethnic Group}

People of different ethnic groups may have different attitudes and behaviors toward the epidemic. Further research is needed to examine the different responses of different ethnic groups to the epidemic (Rubin et al., 2009). Moreover, ethnic groups may have different degrees of xenophobia due to fear of coronavirus, and more research is needed to understand the relationship between coronavirus phobia and coronavirus-related xenophobia, and the possible role of individual difference variables (e.g., susceptibility to disease) within an ethnic group (Taylor, 2019).

\section{Economic Development}

Future research may examine the relationships between economic development and the impact of the pandemic on mental health based on the economic status of different countries, and explore 
solutions to the severe psychosocial health phenomena that may be caused by socio-economic crises in economically underdeveloped countries amid a large scale crisis.

\section{Country}

Relatively little research is focused on how psychological distress caused by the pandemic varies across countries. Future studies can compare and analyze the differences in the level of psychological distress in different countries with different economic conditions. As countries have achieved varying degrees of success in controlling the spread of the COVID-19 virus (Patel and Rietveld, 2020). Future research based on international data can further explore the level of psychological distress in countries where government interventions are relatively successful, in comparison with those countries that are not so successful.

\section{Long-Term Effects}

As the COVID-19 pandemic continues to evolve, the sources of psychological distress surrounding the pandemic and the degree of psychological distress may change (Piltch-Loeb et al., 2021). The extant research mainly focuses on the early or short-term psychological impact of the pandemic. Long-term longitudinal research should be added in the future to investigate the sources of psychological and mental distress at different time points (Magnavita et al., 2020). Although a large number of studies have found a positive relationship between the economic uncertainty (or difficulties) and mental health problems, other studies do not degree with the relationship between deteriorating mental health and the level of job insecurity and financial impact (Kwong et al., 2020). Further empirical research is needed to understand the interrelationships among various antecedents and how different factors mediate or moderate the relationship between the pandemic and mental health.

\section{REFERENCES}

Ahmed, M. Z., Ahmed, O., Aibao, Z., Hanbin, S., Siyu, L., and Ahmad, A. (2020). Epidemic of COVID-19 in China and associated psychological problems. Asian J. Psychiatr. 51:102092. doi: 10.1016/j.ajp.2020.102092

Ai, X., Yang, J., Lin, Z., and Wan, X. (2021). Mental health and the role of physical activity during the COVID-19 pandemic. Front. Psychol. doi: 10.3389/ fpsyg.2021.759987 (in press).

Alauddin, M., Khan, F., Imtiaz, S., Ahmed, S., and Amyotte, P. (2021). Pandemic risk management using engineering safety principles. Process Saf. Environ. Prot. 150, 416-432. doi: 10.1016/j.psep.2021.04.014

Ali, M., Ahsan, G. U., Khan, R., Khan, H. R., and Hossain, A. (2020). Immediate impact of stay-at-home orders to control COVID-19 transmission on mental well-being in Bangladeshi adults: patterns, explanations, and future directions. BMC. Res. Notes 13:494. doi: 10.1186/s13104-020-05345-2

Ali, M., Uddin, Z., and Hossain, A. (2021). Economic stressors and mental health symptoms among Bangladeshi rehabilitation professionals: a crosssectional study amid COVID-19 pandemic. Heliyon 7:e06715. doi: 10.1016/j. heliyon.2021.e06715

Asmundson, G. J. G., Abramowitz, J. S., Richter, A. A., and Whedon, M. (2010). Health anxiety: current perspectives and future directions. Curr. Psychiatry Rep. 12, 306-312. doi: 10.1007/s11920-010-0123-9

Asmundson, G. J. G., and Taylor, S. (2020a). Coronaphobia: fear and the 2019nCoV outbreak. J. Anxiety Disord. 70:102196. doi: 10.1016/j.janxdis.2020.102196

\section{CONCLUSION}

This conceptual analysis article explores two mechanisms (i.e., economic distress and employment distress) that lead to the deterioration of individuals' mental health. The proposed conceptual framework explains how the COVID-19 pandemic and public health interventions affect people's mental health, the responding coping behaviors. The extant literature provides evidence supporting the hypothesis that the COVID-19 pandemic and its associated measures increase individual economic uncertainty and employment uncertainty, thereby triggering mental health problems and coping behaviors. The findings of most studies support this mechanism from the onset of the pandemic to the emergence of economic distress and employment distress, to the deterioration of mental health, and then to changes in people's behaviors. Supportive evidence was found in different countries (e.g., the United States, China, Bangladesh, Italy, etc.) and in different groups (elderly, young, disabled, mentally ill, etc.).

\section{AUTHOR CONTRIBUTIONS}

XL: conceptualization, methodology, and writing - original draft preparation. ZL: conceptualization and writing - reviewing and editing. All authors contributed to the article and approved the submitted version.

\section{FUNDING}

This research was supported by the Educational Commission of Fujian Province of China (grant no. JAS20129) and the Science Foundation of Jimei University, China.

Asmundson, G. J. G., and Taylor, S. (2020b). How health anxiety influences responses to viral outbreaks like COVID-19: what all decision-makers, health authorities, and health care professionals need to know. J. Anxiety Disord. 71:102211. doi: 10.1016/j.janxdis.2020.102211

Auerbach, J., and Miller, B. F. (2020). COVID-19 exposes the cracks in our already fragile mental health system. Am. J. Public Health 110, 969-970. doi: 10.2105/AJPH.2020.305699

Bauer, A., Garman, E., McDaid, D., Avendano, M., Hessel, P., Díaz, Y., et al. (2021). Integrating youth mental health into cash transfer programmes in response to the COVID-19 crisis in low-income and middle-income countries. Lancet Psychiatry 8, 340-346. doi: 10.1016/S2215-0366(20)30382-5

Bierman, A., Upenieks, L., Glavin, P., and Schieman, S. (2021). Accumulation of economic hardship and health during the COVID-19 pandemic: social causation or selection? Soc. Sci. Med. 275:113774. doi: 10.1016/j. socscimed.2021.113774

Cacioppo, J. T., Hughes, M. E., Waite, L. J., Hawkley, L. C., and Thisted, R. A. (2006). Loneliness as a specific risk factor for depressive symptoms: crosssectional and longitudinal analyses. Psychol. Aging 21, 140-151. doi: 10.1037/0882-7974.21.1.140

Cheng, S. K. W., Wong, C. W., Tsang, J., and Wong, K. C. (2004). Psychological distress and negative appraisals in survivors of severe acute respiratory syndrome (SARS). Psychol. Med. 34, 1187-1195. doi: 10.1017/S0033291704002272

Długosz, P. (2021). Factors influencing mental health among American youth in the time of the Covid-19 pandemic. Personal. Individ. Differ. 175:110711. doi: $10.1016 /$ j.paid.2021.110711 
Dooley, D., Prause, J., and Ham-Rowbottom, K. A. (2000). Underemployment and depression: longitudinal relationships. J. Health Soc. Behav. 41, 421-436. doi: $10.2307 / 2676295$

Drydakis, N. (2015). The effect of unemployment on self-reported health and mental health in Greece from 2008 to 2013: a longitudinal study before and during the financial crisis. Soc. Sci. Med. 128, 43-51. doi: 10.1016/j.socscimed.2014.12.025

Ferry, F., Bunting, B., Rosato, M., Curran, E., and Leavey, G. (2021). The impact of reduced working on mental health in the early months of the COVID-19 pandemic: results from the understanding society COVID-19 study. J. Affect. Disord. 287, 308-315. doi: 10.1016/j.jad.2021.03.042

Fiori, F., Rinesi, F., Spizzichino, D., and Di Giorgio, G. (2016). Employment insecurity and mental health during the economic recession: an analysis of the young adult labour force in Italy. Soc. Sci. Med. 153, 90-98. doi: 10.1016/j. socscimed.2016.02.010

Fisher, J., Tran, T., Hammarberg, K., Nguyen, H., Stocker, R., Rowe, H., et al. (2021). Quantifying the mental health burden of the most severe covid-19 restrictions: a natural experiment. J. Affect. Disord. 293, 406-414. doi: 10.1016/j. jad.2021.06.060

Fragkaki, I., Maciejewski, D. F., Weijman, E. L., Feltes, J., and Cima, M. (2021). Human responses to Covid-19: the role of optimism bias, perceived severity, and anxiety. Personal. Individ. Differ. 176:110781. doi: 10.1016/j.paid.2021.110781

Gössling, S., Scott, D., and Hall, C. M. (2021). Pandemics, tourism and global change: a rapid assessment of COVID-19. J. Sustain. Tour. 29, 1-20. doi: 10.1080/09669582.2020.1758708

Han, Q., Zheng, B., Agostini, M., Bélanger, J. J., Gützkow, B., Kreienkamp, J., et al. (2021). Associations of risk perception of COVID-19 with emotion and mental health during the pandemic. J. Affect. Disord. 284, 247-255. doi: 10.1016/j.jad.2021.01.049

Hao, F., Tan, W., Jiang, L., Zhang, L., Zhao, X., Zou, Y., et al. (2020). Do psychiatric patients experience more psychiatric symptoms during COVID-19 pandemic and lockdown? A case-control study with service and research implications for immunopsychiatry. Brain Behav. Immun. 87, 100-106. doi: 10.1016/j.bbi.2020.04.069

Hawkley, L. C., and Cacioppo, J. T. (2010). Loneliness matters: a theoretical and empirical review of consequences and mechanisms. Ann. Behav. Med. 40, 218-227. doi: 10.1007/s12160-010-9210-8

Hjemdal, O., Vogel, P. A., Solem, S., Hagen, K., and Stiles, T. C. (2011). The relationship between resilience and levels of anxiety, depression, and obsessivecompulsive symptoms in adolescents. Clin. Psychol. Psychother. 18, 314-321. doi: $10.1002 /$ cpp.719

Holmes, E. A., Connor, R. C. O., Perry, V. H., Tracey, I., Wessely, S., Arseneault, L., et al. (2020). Multidisciplinary research priorities for the COVID-19 pandemic: a call for action for mental health science. Lancet Psychiatry 7, 547-560. doi: 10.1016/s2215-0366(20)30168-1

Hossain, A., and Ali, M. (2021). Prevalence of mental health symptoms and its effect on insomnia among healthcare workers who attended hospitals during COVID-19 pandemic: a survey in Dhaka city. Heliyon 7. doi: 10.1016/j. heliyon.2021.e06985

Hossain, I., Mullick, A., Haidar, A., and Aktaruzzaman, M. M. (2020). The COVID-19 pandemic and mental health: a systemic review. Texila Int. J. Acad. Res. 7. doi: 10.21522/TIJAR.2014.07.01.Art023

$\mathrm{Hu}$, Y., and Qian, Y. (2021). COVID-19 and adolescent mental health in the United Kingdom. J. Adolesc. Health 69, 26-32. doi: 10.1016/j.jadohealth.2021.04.005

Jetten, J., Haslam, S., Cruwys, T., Greenaway, K., Haslam, C., and Steffens, N. K. (2017). Advancing the social identity approach to health and well-being: progressing the social cure research agenda. Eur. J. Soc. Psychol. 47. doi: 10.1002/ejsp.2333

Jin, R. L., Shah, C. P., and Svoboda, T. J. (1997). The impact of unemployment on health: a review of the evidence. J. Public Health Policy 18, 275-301. doi: $10.2307 / 3343311$

Jung, S. J., Jeon, Y. J., Yang, J. S., Park, M., Kim, K., Chibnik, L. B., et al. (2021). Impact of COVID-19 on mental health according to prior depression status: a mental health survey of community prospective cohort data. J. Psychosom. Res. 148:110552. doi: 10.1016/j.jpsychores.2021.110552

Jungmann, S. M., and Witthöft, M. (2020). Health anxiety, cyberchondria, and coping in the current COVID-19 pandemic: which factors are related to coronavirus anxiety? J. Anxiety Disord. 73:102239. doi: 10.1016/j. janxdis.2020.102239

Karatepe, O. M., Saydam, M. B., and Okumus, F. (2021). COVID-19, mental health problems, and their detrimental effects on hotel employees' propensity to be late for work, absenteeism, and life satisfaction. Curr. Issue Tour. 24, 934-951. doi: 10.1080/13683500.2021.1884665

Karney, B. (2020). Socioeconomic status and intimate relationships. Annu. Rev. Psychol. 72, 391-414. doi: 10.1146/annurev-psych-051920-013658

Kim, S. S., Kim, J., Badu-Baiden, F., Giroux, M., and Choi, Y. (2021). Preference for robot service or human service in hotels? Impacts of the COVID-19 pandemic. Int. J. Hosp. Manag. 93:102795. doi: 10.1016/j.ijhm.2020.102795

Kimhi, S., Marciano, H., Eshel, Y., and Adini, B. (2020). Recovery from the COVID-19 pandemic: distress and resilience. Int. J. Disaster Risk Reduct. 50:101843. doi: 10.1016/j.ijdrr.2020.101843

Kwong, A. S. F., Pearson, R. M., Adams, M. J., Northstone, K., Tilling, K., Smith, D., et al. (2020). Mental health during the COVID-19 pandemic in two longitudinal UK population cohorts. medRxiv. doi: 10.1101/2020.06.16.20133116, [Epub ahead of print].

Le, H. T., Lai, A. J. X., Sun, J., Hoang, M. T., Vu, L. G., Pham, H. Q., et al. (2020). Anxiety and depression among people under the nationwide partial lockdown in Vietnam. Front. Public Health 8:656. doi: 10.3389/fpubh.2020.589359

Magnavita, N., Tripepi, G., and Di Prinzio, R. R. (2020). Symptoms in health care workers during the COVID-19 epidemic. A cross-sectional survey. Int. J. Environ. Res. Public Health 17:5218. doi: 10.3390/ijerph17145218

Mann, F. D., Krueger, R. F., and Vohs, K. D. (2020). Personal economic anxiety in response to COVID-19. Personal. Individ. Differ. 167:110233. doi: 10.1016/j. paid.2020.110233

McKay, D., Yang, H., Elhai, J., and Asmundson, G. J. G. (2020). Anxiety regarding contracting COVID-19 related to interoceptive anxiety sensations: the moderating role of disgust propensity and sensitivity. J. Anxiety Disord. 73:102233. doi: 10.1016/j.janxdis.2020.102233

Mehta, P., McAuley, D. F., Brown, M., Sanchez, E., Tattersall, R. S., and Manson, J. J. (2020). COVID-19: consider cytokine storm syndromes and immunosuppression. Lancet 395, 1033-1034. doi: 10.1016/S0140-6736(20)30628-0

Meltzer, M. I., Cox, N. J., and Fukuda, K. (1999). The economic impact of pandemic influenza in the United States: priorities for intervention. Emerg. Infect. Dis. 5, 659-671. doi: 10.3201/eid0505.990507

Mikocka-Walus, A., Stokes, M., Evans, S., Olive, L., and Westrupp, E. (2021). Finding the power within and without: how can we strengthen resilience against symptoms of stress, anxiety, and depression in Australian parents during the COVID-19 pandemic? J. Psychosom. Res. 145:110433. doi: 10.1016/j.jpsychores.2021.110433

Milner, A., Page, A., and LaMontagne, A. (2013). Long-term unemployment and suicide: a systematic review and meta-analysis. PLoS One 8:e51333. doi: 10.1371/journal.pone.0051333

Mobbs, D., Hagan, C. C., Dalgleish, T., Silston, B., and Prévost, C. (2015). The ecology of human fear: survival optimization and the nervous system. Front. Neurosci. 9:55. doi: 10.3389/fnins.2015.00055

Murakami, M., Kobayashi, T., Oikawa, Y., Goto, S., Momoi, M., Takebayashi, Y., et al. (2021). Associations of the COVID-19 pandemic with the economic status and mental health of people affected by the Fukushima disaster using the difference-in-differences method: the Fukushima health management survey. SSM Popul. Health 14:100801. doi: 10.1016/j.ssmph.2021.100801

Nagelhout, G. E., Hummel, K., de Goeij, M. C. M., de Vries, H., Kaner, E., and Lemmens, P. (2017). How economic recessions and unemployment affect illegal drug use: a systematic realist literature review. Int. J. Drug Policy 44, 69-83. doi: 10.1016/j.drugpo.2017.03.013

Nayal, P., Pandey, N., and Paul, J. (2021). Covid-19 pandemic and consumeremployee-organization wellbeing: a dynamic capability theory approach. $J$. Consum. Aff. doi: 10.1111/joca.12399 [Epub ahead of print].

Odayar, J., Myer, L., and Malaba, T. R. (2020). The epidemiology and pathogenesis of SARS-CoV-2 infection in pregnancy: more questions than answers EClinicalMedicine 26:100534. doi: 10.1016/j.eclinm.2020.100534

Omar, N. A., Nazri, M. A., Ali, M. H., and Alam, S. S. (2021). The panic buying behavior of consumers during the COVID-19 pandemic: examining the influences of uncertainty, perceptions of severity, perceptions of scarcity, and anxiety. J. Retail. Consum. Serv. 62:102600. doi: 10.1016/j.jretconser.2021.102600

Oomens, S., Geurts, S., and Scheepers, P. (2007). Combining work and family in the Netherlands: blessing or burden for one's mental health? Int. J. Law Psychiatry 30, 369-384. doi: 10.1016/j.ijlp.2007.06.009

Patel, P. C., and Rietveld, C. A. (2020). The impact of financial insecurity on the self-employed's short-term psychological distress: evidence from the COVID-19 pandemic. J. Bus. Ventur. Insights 14:e00206. doi: 10.1016/j. jbvi.2020.e00206 
Pettinicchio, D., Maroto, M., Chai, L., and Lukk, M. (2021). Findings from an online survey on the mental health effects of COVID-19 on Canadians with disabilities and chronic health conditions. Disabil. Health J. 14:101085. doi: 10.1016/j.dhjo.2021.101085

Pfefferbaum, B., and North, C. S. (2020). Mental health and the covid-19 pandemic. N. Engl. J. Med. 383, 510-512. doi: 10.1056/NEJMp2008017

Pharr, J. R., Moonie, S., Bungum, T. J., Allam, M. F., Bendtsen, P., and Al-Faris, E. A. (2012). The impact of unemployment on mental and physical health, access to health care and health risk behaviors. ISRN Public Health 2012:483432. doi: $10.5402 / 2012 / 483432$

Pierce, M., Hope, H., Ford, T., Hatch, S., Hotopf, M., John, A., et al. (2020). Mental health before and during the COVID-19 pandemic: a longitudinal probability sample survey of the UK population. Lancet Psychiatry:7, 883-892. doi: 10.1016/S2215-0366(20)30308-4

Piltch-Loeb, R., Merdjanoff, A., and Meltzer, G. (2021). Anticipated mental health consequences of COVID-19 in a nationally-representative sample: context, coverage, and economic consequences. Prev. Med. 145:106441. doi: 10.1016/j.ypmed.2021.106441

Prati, G., Pietrantoni, L., and Zani, B. (2011). A social-cognitive model of pandemic influenza H1N1 risk perception and recommended behaviors in Italy. Risk Anal. 31, 645-656. doi: 10.1111/j.1539-6924.2010.01529.x

Rajkumar, R. P. (2020). COVID-19 and mental health: a review of the existing literature. Asian J. Psychiatr. 52:102066. doi: 10.1016/j.ajp.2020.102066

Ribeiro, F., Schröder, V. E., Krüger, R., and Leist, A. K. (2021). The evolution and social determinants of mental health during the first wave of the COVID-19 outbreak in Luxembourg. Psychiatry Res. 303:114090. doi: 10.1016/j. psychres.2021.114090

Rimé, B. (2009). Emotion elicits the social sharing of emotion: theory and empirical review. Emot. Rev. 1, 60-85. doi: 10.1177/1754073908097189

Roos, P., Gelfand, M., Nau, D., and Lun, J. (2015). Societal threat and cultural variation in the strength of social norms: an evolutionary basis. Organ. Behav. Hum. Decis. Process. 129, 14-23. doi: 10.1016/j.obhdp.2015.01.003

Rossi, R., Socci, V., Talevi, D., Mensi, S., Niolu, C., Pacitti, F., et al. (2020). COVID-19 pandemic and lockdown measures impact on mental health among the general population in Italy. Front. Psych. 11:790. doi: 10.3389/fpsyt.2020.00790

Rubin, G. J., Amlôt, R., Page, L., and Wessely, S. (2009). Public perceptions, anxiety, and behaviour change in relation to the swine flu outbreak: cross sectional telephone survey. BMJ 339:b2651. doi: 10.1136/bmj.b2651

Salameh, P., Hajj, A., Badro, D. A., Abou Selwan, C., Aoun, R., and Sacre, H. (2020). Mental health outcomes of the COVID-19 pandemic and a collapsing economy: perspectives from a developing country. Psychiatry Res. 294:113520. doi: 10.1016/j.psychres.2020.113520

Salari, N., Hosseinian-Far, A., Jalali, R., Vaisi-Raygani, A., Rasoulpoor, S., Mohammadi, M., et al. (2020). Prevalence of stress, anxiety, depression among the general population during the COVID-19 pandemic: a systematic review and meta-analysis. Glob. Health 16:57. doi: 10.1186/s12992-020-00589-w

Schroeder, J., Kardas, M., and Epley, N. (2017). The humanizing voice: speech reveals, and text conceals, a more thoughtful mind in the midst of disagreement. Psychol. Sci. 28, 1745-1762. doi: 10.1177/0956797617713798

Shammi, M., Bodrud-Doza, M., Towfiqul Islam, A. R. M., and Rahman, M. M. (2020). COVID-19 pandemic, socioeconomic crisis and human stress in resource-limited settings: A case from Bangladesh. Heliyon 6:e04063. doi: 10.1016/j.heliyon.2020.e04063

Sirviö, A., Ek, E., Jokelainen, J., Koiranen, M., Järvikoski, T., and Taanila, A. (2012). Precariousness and discontinuous work history in association with health. Scand. J. Public Health 40, 360-367. doi: 10.1177/1403494812450092

Tan, W., Hao, F., McIntyre, R. S., Jiang, L., Jiang, X., Zhang, L., et al. (2020). Is returning to work during the COVID-19 pandemic stressful? A study on immediate mental health status and psychoneuroimmunity prevention measures of Chinese workforce. Brain Behav. Immun. 87, 84-92. doi: 10.1016/j. bbi.2020.04.055

Taylor, S. (2019). The Psychology of Pandemics: Preparing for the Next Global Outbreak of Infectious Disease. Newcastle upon Tyne, UK: Cambridge Scholars Publishing.

Taylor, S., and Asmundson, G. J. G. (2004). Treating Health Anxiety: A CognitiveBehavioral Approach: Guilford, New York.

Tee, M., Wang, C., Tee, C., Pan, R., Reyes, P. W., Wan, X., et al. (2021). Impact of the COVID-19 pandemic on physical and mental health in lower and upper middle-income Asian countries: A comparison between the Philippines and China. Front. Psych. 11:1631. doi: 10.3389/fpsyt.2020.568929
Thomas, C., Benzeval, M., and Stansfeld, S. (2007). Psychological distress after employment transitions: the role of subjective financial position as a mediator. J. Epidemiol. Community Health 61, 48-52. doi: 10.1136/jech.2005.044206

Timming, A. R., French, M. T., and Mortensen, K. (2021). Health anxiety versus economic anxiety surrounding COVID-19:an analysis of psychological distress in the early stages of the pandemic. J. Affect. Disord. Rep. 5:100152. doi: $10.1016 /$ j.jadr.2021.100152

Uutela, A. (2010). Economic crisis and mental health. Curr. Opin. Psychiatry 23, 127-130. doi: 10.1097/YCO.0b013e328336657d

Van Bavel, J. J., Baicker, K., Boggio, P. S., Capraro, V., Cichocka, A., Cikara, M., et al. (2020). Using social and behavioural science to support COVID-19 pandemic response. Nat. Hum. Behav. 4, 460-471. doi: 10.1038/s41562-020-0884-z

Wang, C., Chudzicka-Czupała, A., Grabowski, D., Pan, R., Adamus, K., Wan, X., et al. (2020a). The association between physical and mental health and face mask use during the COVID-19 pandemic: A comparison of two countries with different views and practices. Front. Psych. 11:569981. doi: 10.3389/fpsyt.2020.569981

Wang, C., Pan, R., Wan, X., Tan, Y., Xu, L., Ho, C. S., et al. (2020b). Immediate psychological responses and associated factors during the initial stage of the 2019 coronavirus disease (COVID-19) epidemic among the general population in China. Int. J. Environ. Res. Public Health 17:1729. doi: 10.3390/ ijerph17051729

Wang, C., Tee, M., Roy, A. E., Fardin, M. A., Srichokchatchawan, W., Habib, H. A., et al. (2021). The impact of COVID-19 pandemic on physical and mental health of Asians: A study of seven middle-income countries in Asia. PLoS One 16:e246824. doi: 10.1371/journal.pone.0246824

Waytz, A., and Gray, K. (2018). Does online technology make us more or less sociable? A preliminary review and call for research. Perspect. Psychol. Sci. 13, 473-491. doi: 10.1177/1745691617746509

Wheaton, M. G., Abramowitz, J. S., Berman, N. C., Fabricant, L. E., and Olatunji, B. O. (2012). Psychological predictors of anxiety in response to the H1N1 (swine flu) pandemic. Cogn. Ther. Res. 36, 210-218. doi: 10.1007/s10608-011-9353-3

Williams, W., Morelli, S., Ong, D., and Zaki, J. (2018). Interpersonal emotion regulation: implications for affiliation, perceived support, relationships, and well-being. J. Pers. Soc. Psychol. 115, 224-254. doi: 10.1037/pspi0000132

Wilson, J., Lee, J., Fitzgerald, H., Oosterhoff, B., Sevi, B., and Shook, N. (2020). Job insecurity and financial concern during the COVID-19 pandemic are associated with worse mental health. J. Occup. Environ. Med. doi: 10.1097/ JOM.0000000000001962 [Epub ahead of print].

World Health Organization. (2020). Mental health and psychosocial considerations during the COVID-19 outbreak. Available at: https://apps.who.int/iris/ handle/10665/331490 (Accessed March 18, 2020).

Xiong, J., Lipsitz, O., Nasri, F., Lui, L. M. W., Gill, H., Phan, L., et al. (2020). Impact of COVID-19 pandemic on mental health in the general population: a systematic review. J. Affect. Disord. 277, 55-64. doi: 10.1016/j. jad.2020.08.001

Yin, J., and Ni, Y. (2021). COVID-19 event strength, psychological safety, and avoidance coping behaviors for employees in the tourism industry. J. Hosp. Tour. Manag. 47, 431-442. doi: 10.1016/j.jhtm.2021.04.017

Zajacova, A., Jehn, A., Stackhouse, M., Choi, K. H., Denice, P., Haan, M., et al. (2020). Mental health and economic concerns from March to May during the COVID-19 pandemic in Canada: insights from an analysis of repeated crosssectional surveys. SSM Popul. Health 12:100704. doi: 10.1016/.jssmph.2020.100704

Conflict of Interest: The authors declare that the research was conducted in the absence of any commercial or financial relationships that could be construed as a potential conflict of interest.

Publisher's Note: All claims expressed in this article are solely those of the authors and do not necessarily represent those of their affiliated organizations, or those of the publisher, the editors and the reviewers. Any product that may be evaluated in this article, or claim that may be made by its manufacturer, is not guaranteed or endorsed by the publisher.

Copyright $\odot 2021 \mathrm{Lu}$ and Lin. This is an open-access article distributed under the terms of the Creative Commons Attribution License (CC BY). The use, distribution or reproduction in other forums is permitted, provided the original author(s) and the copyright owner(s) are credited and that the original publication in this journal is cited, in accordance with accepted academic practice. No use, distribution or reproduction is permitted which does not comply with these terms. 